\title{
АНАЛИЗ ИНТЕГРАЦИИ ЦИФРОВОЙ ЭКОНОМИКИ В ПРОЦЕСС ОБЩЕСТВЕННО-ЭКОНОМИЧЕСКОГО ВОСПРОИЗВОДСТВА
}

\author{
(c) 2019 Мокичев Сергей Дмитриевич \\ кандидат экономических наук, доцент кафедры экономической теории и эконометрики \\ Казанский (Приволжский) федеральный университет, Россия, Казань \\ E-mail: mokichev.kpfu@mail.ru
}

(c) 2019 Иванов Сергей Евгеньевич

преподаватель кафедры сервиса и туризма

Поволжская академия физической культуры, спорта и туризма, Россия, Казань

\section{(C) 2019 Фатхуллин Альберт Рашитович}

старший преподаватель кафедры управления человеческими ресурсами

Казанский (Приволжский) федеральный университет, Россия, Казань

В статье анализируются особенности формирования цифровой экономики в том числе в развивающихся странах и России. Пути и направления, которые могут отличаться от развитых стран в связи с условиями взаимодействия с цифровым капиталом и его аллокацией. В рамках этого уделяется внимание вопросу отношений собственности на средства производства цифровых продуктов и услуг, необходимых для развития механизма цифровизации и цифровой экосреды. Исследуется необходимость формализации направлений цифровизации экономики, движущих сил и создающих инструментов для эффективного функционирования институциональной среды.

Ключевые слова: Цифровая экономика, Цифровизация, Интеллектуальная собственность, Экономическая теория, Цифровая экосистема, Информационные технологии, Развитие.

В последние несколько лет отчётливо наблюдается сдвиг мировых экономических тенденций развития в сторону формирования и реализации цифровой экономики. Ведутся обширные дискуссии как на локальных, так и на мировых научных площадках по поводу формирования методологии и институциональной среды цифровизации. Особое внимание аспектам цифровой экономики уделяется на Международном экономическом форуме, встречах ООН, саммитах стран Большой двадцатки, по итогам которых формируются отчеты, описывающие ход и результаты дискуссий, которые отчасти ложатся в основу данной статьи. Многими общественными организациями и учёным рассматриваются не только аспекты современного состояния и прогресса цифровой экономики западного мира и развитых стран, но большое внимание уделяется странам с развивающейся экономикой и развивающимся рынкам, которые зачастую показывают гораздо более высокие темпы освоения и использования информационных технологий, но, естественно, они имеют ряд свойственных ограничений в экономической и правовой сфеpax. Однако, несмотря на вовлеченность в ис- следование данной проблемы, до сих пор, не только в России, но и в мире, не существует четкой формализованной методологии развития и функционирования цифровой экономики отчасти ввиду новизны проблематики этой сферы, отчасти ввиду чрезвычайно высокой скорости изменений в информационной среде, в структуре и составе современной технологической базы. Особенности современного технологического развития, а также возможные подходы к принятию нестандартных решений по выбору технологических приоритетов рассматривает в своей статье Попов Е.В., делая акцент на влиянии технологических факторов и способности управления информационными системами. Во многом раскрывается спектр данных для анализа и выработки понятия цифровой экономики в статье Бухта Р. и Хикса Р., где широко исследуется цифровой сектор, а также предприятия и сферы информационно-коммуникационных технологий, которые производят основные цифровые продукты и услуги.

Цифровые технологии распространяются по всему миру более быстрыми темпами, чем предыдущие волны технологических инноваций, и 
изменяют бизнес-модели и секторы [5]. Это преобразование включает в себя появление цифровой экономики. Определяемая как «та часть экономического производства, которая производится исключительно или в основном за счет цифровых технологий с бизнес-моделью, основанной на цифровых товарах или услугах», цифровая экономика, по оценкам, составляет около $5 \%$ мирового ВВП и $3 \%$ глобальной занятости [4].

Рассматривая особенность скорости внедрения и распространения цифровых и мобильных технологий (рис.1, рис.2), которая увеличивается в геометрической прогрессии, а вместе с тем происходит рост денежных потоков, проходящих через эти экономические процессы, можно достичь понимания катастрофической сложности стоящей перед исследователями задачи формирования теоретико-методологического аппарата, позволяющего улучшить восприятие и увеличить эффективность и раскрыть потенциал цифровой экономики.

Все лица, которые пользовались Интернетом за последние 3 месяца, считаются пользователями Интернета. Интернет можно использовать через компьютер, мобильный телефон, персонального цифрового помощника, игровой автомат, цифровое телевидение и т.д. (рис. 1).
Вид коммуникационной отрасли очень сильно изменилось по прошествии последних лет опираясь на два столпа - инноваций и сотрудничества. Частный сектор сыграл большую роль в обоих. Инновации стали прямым следствием конкуренции на рынке, в то время как сотрудничество между участниками отрасли является подлинным результатом стратегического предвидения и прогрессивного мышления, которое позволяет рассматривать более широкие проблемы отрасли в перспективе. Стратегическое сотрудничество, такое как пассивное совместное использование инфраструктуры, быстро сократило стоимость развертывания. Теперь пришло время перейти на следующий уровень и совместно использовать активную инфраструктуру посредством формирования сетевых компаний. Это поможет высвободить больше инвестиций для расширения рынка и обеспечить лучшее качество обслуживания клиентов. Частному сектору также придется экспериментировать с инновационными механизмами финансирования и доступа к рынкам, чтобы стимулировать инвестиции в рыночную инфраструктуру.

Обеспечение проникновения цифровых услуг на развивающиеся рынки является двоякой задачей: во-первых, низкая покупательская спо-

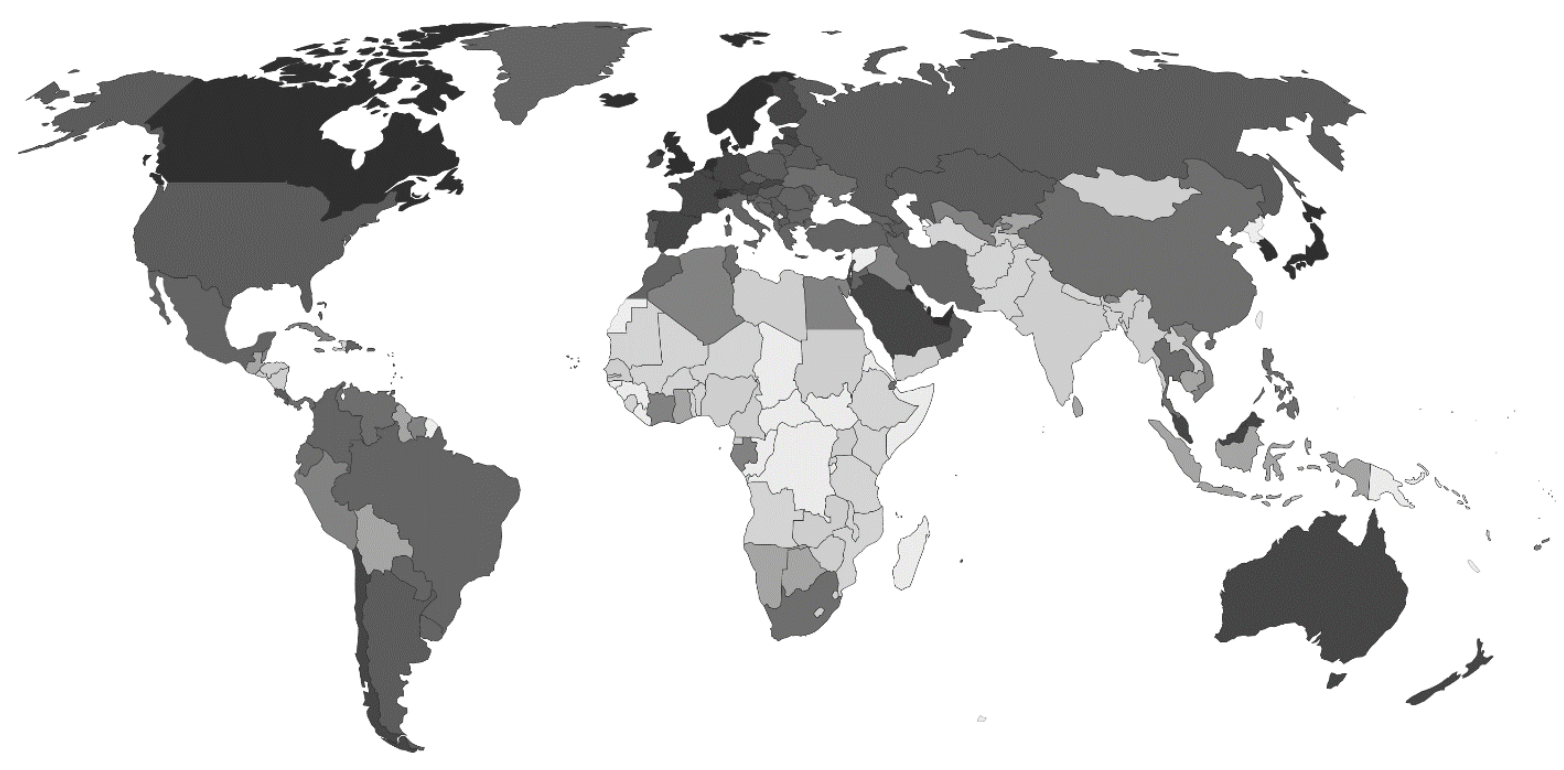

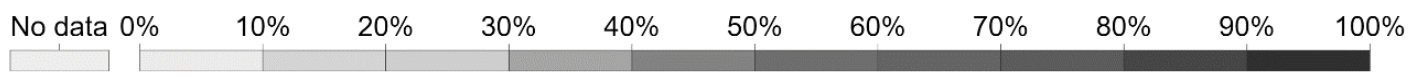

Puc. 1. Доля населения использующая Интернет, по данным на 2017 [8] Источник: Всемирный Банк [http://data.worldbank.org/data-catalog/world-development-indicators] Графика: [ourworldindata.org] 


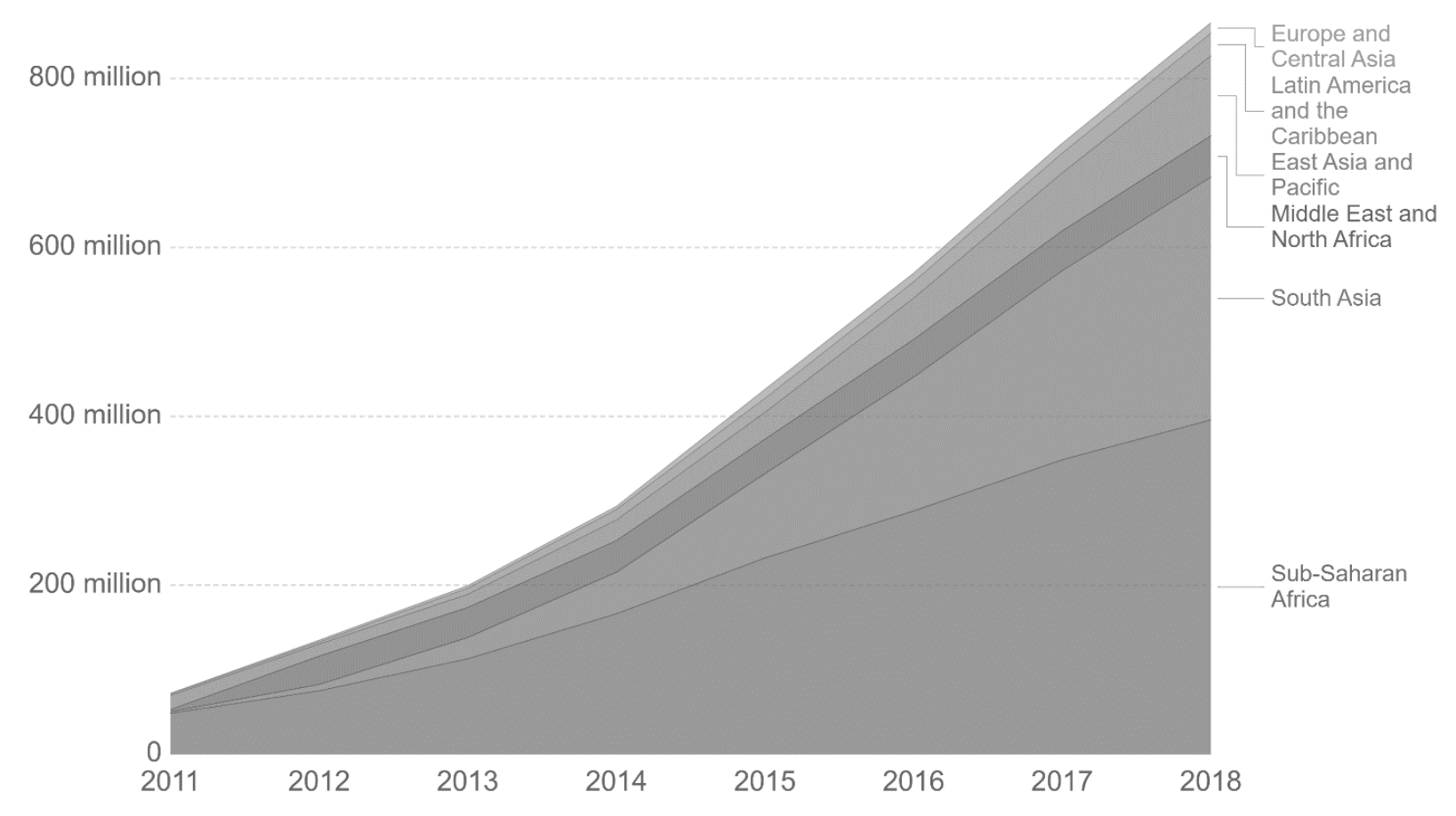

Puc. 2. Зарегистрированные мобильные денежные счета по регионам на 2018 [6]

Источник: GSMA [https://www.gsma.com/mobilemoneymetrics/] Графика: [ourworldindata.org]

собность ведет к снижению Средней выручки на одного пользователя (ARPU - Average Revenue Per User); во-вторых, отсутствие приложений на местном языке, которые препятствуют адаптации. Необходима активная локальная прикладная система, ориентированная на решение местных потребностей. Помимо оказания помощи в создании динамичной инфраструктуры, правительство и регулирующие органы должны будут сосредоточиться на деятельности по всей цепочке создания стоимости, принимая всестороннее представление об этом секторе [7].

В докладе Высшей школы экономики достаточно чётко сформулированы основные сложности в процессе трансформации общества в условиях развития цифровой экономики, где были отмечены такие аспекты как: возникновение «умного» общества, базирующегося на новых ценностях ориентации на потребности человека, гибкости, креативности, что неразрывно связанно с трансформациями рынка труда, здравоохранения, образования и общественной инфраструктуры; модернизация и персонализация современной медицины за счёт возможности постоянного мониторинга здоровья человека при помощи информационных технологий; развитие биоинформатики и генной инженерии, где появляется возможность существенно сократить время и стоимость проведения исследований; вместе с тем Цифровизация является причиной усложнения и исчезновения ряда профессий, что не может не повлечь за собой повышение уровня безработицы, возможно даже в глобальных масштабах, развиваются транснациональные формы образовательной деятельности (Cross-Border Education), что может приводить как к повышению мобильности, так и к утечке умов из стран с развивающимися экономиками, вместе с тем возрастает потребность решения проблем связанных с адаптацией образования к цифровой экосреде; стремительно увеличивающийся объём данных значительно превосходит возможности человека к их усвоению и обработки, что однозначно в ещё большей степени увеличивает спрос на ИТ и требует совершенствования информационной и технологической грамотности населения; цифровые услуги и современный подход к организации «умных пространств» меняют условия жизни на более комфортные, представляя собой физическую или цифровую среду, в которой люди открыто взаимодействуют друг с другом и с ИИ, однако под вопросом оказались традиционные принципы территориальности и, вместе с тем, распределения стоимости; развитие Интернета вещей создаёт удобную и прозрачную среду для 
сделок, но также возникает и повышается спрос как на технологии кибербезопасности, так и на технологии киберпреступности [2].

Принимая во внимание всю динамичность, сложность и многогранность сферы информационных технологий и вытекающий отсюда сложносоставной характер цифровой экосистемы, необходимо выделить основные сферы аллокации цифровых продуктов и технологий в которых должны проходить соответствующие институциональные модернизации.

На данной схеме (рис. 3) можно видеть взаимосвязь различных секторов национальной экономической системы, которые образуют цепочки обмена технологиями и формируют конечного потребителя. Естественно, пересечения могут существовать, как внутри этих секторов, так и между ними, потому представленное разделение скорее условно и создано для облегчения понимания распределения внутри экономической системы, отдельно выделяя международные отношения, как более сложную макросистему, которую, безусловно, следует подвергать отдельному анализу. Кроме того, крайне важным является понимание многообразия проблем, возникающих и на стадии формирования, и на стадии функционирования цифровой экономики, что будет создавать образ задач, требующих постоянного внимания и исследования для построения теоретико-методологической основы, которая будет сочетаться с динамикой развития этой сферы и определять направления её использования и разрастания. Здесь можно выделить и структурировать следующие проблемы:

- Особенность формирования и донесения стоимости в условиях цифровой экономики и процессы монетизации данных

- Финансовое обеспечение цифровой экономики

- Ограничения в условиях особенностей развивающихся стран

- Проблематика отношений собственности, в том числе интеллектуальной

- Аллокация цифрового реального и интеллектуального капитала, алгоритм совместного использования

- Асимметрия информации и неравномерность адаптации цифровой экономики

- Языковые, политические, правовые и институциональные барьеры

Решение данных задач однозначно требует масштабного и комплексного подхода, который может быть реализован только через создание национальных стратегических программ по взаимодействию в рамках цифровой экономики, её развитию и регулированию трансформационных процессов в рамках общественного воспроизводства. В связи с этим во многих странах были разработаны цифровые стратегии, сконцентрированные на внедрение инновационных цифровых технологий с целью повышения эффективности функционирования национальных инновационных систем в рамках которых цифровая экосистема, и, в частности, Интернет, как ведущий её элемент, рассматривается как основа экономических модернизационных процессов и структурных преобразований в реальном секторе [3].

Соответствующая стратегическая программа, направленная на освоение и развитие цифровой экономики, существует и в России под названием «ПРОГРАММА «Цифровая экономика

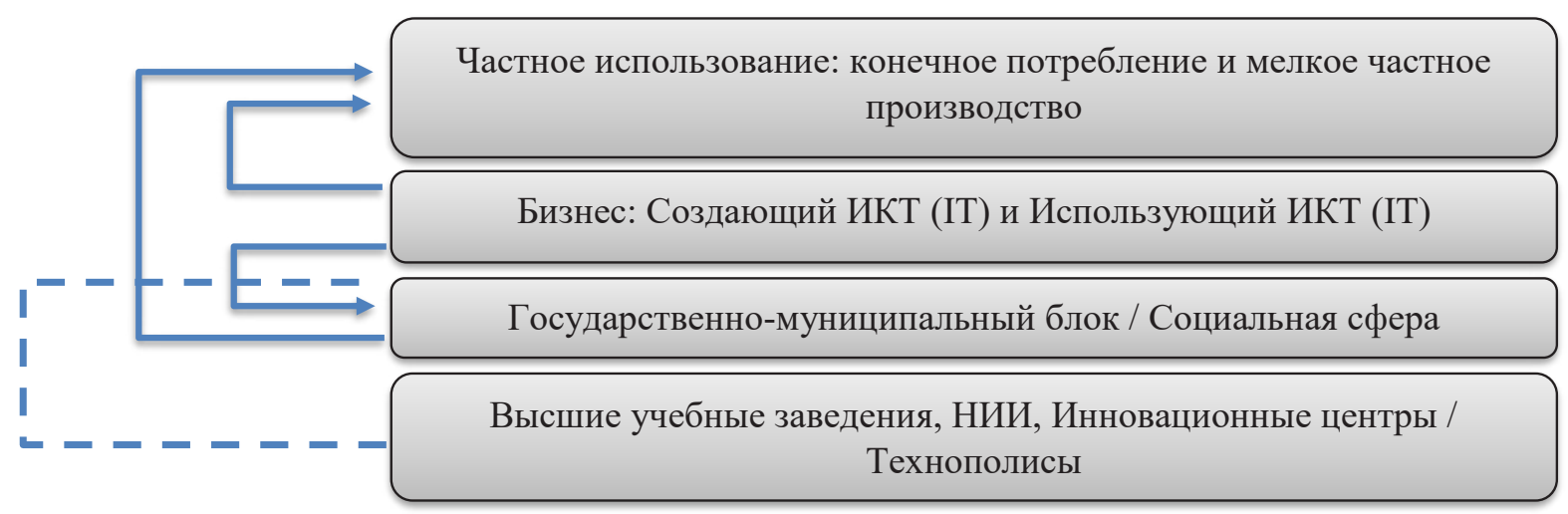

Puc. 3. Взаимосвязь секторов экономики производящих и потребляющих Информационно-коммуникационные технологии (ИКТ (IT))

Составлено авторами 
Стратегии цифрового развития ряда стран ОЕСD (ОЭСР) [3]

\begin{tabular}{|l|l|}
\hline \multicolumn{1}{|c|}{ Страна } & \multicolumn{1}{c|}{ Название стратегии } \\
\hline Австралия & Australian National Digital Economy Strategy \\
\hline Австрия & Strategy for Research, Technology and Innovation (RTI strategy) \\
\hline Канада & $\begin{array}{l}\text { Canada's digital economy strategy built upon the Government's economic plan, } \\
\text { Advantage Canada }\end{array}$ \\
\hline Чехия & Smart Administration Strategy for the period 2007-2015 \\
\hline Эстония & The Estonian Information Society Strategy 2007-2013 \\
\hline ЕС & Digital Agenda for Europe (DAE) \\
\hline Франция & Plan Numérique 2012 \\
\hline Германия & Digital Germany 2015 \\
\hline Венгрия & The Digital Renewal Action Plan \\
\hline Япония & New Strategy in Information and Communications Technology \\
\hline Нидерланды & Digital Agenda.nl \\
\hline Новая Зеландия & Directions and Priorities for Government ICT \\
\hline Норвегия & Digital Agenda for Norway \\
\hline Португалия & Digital Agenda 2015 \\
\hline Испания & Plan Avanza 2 \\
\hline Швеция & Digital Agenda for Sweden \\
\hline Швейцария & Strategy for an Information Society in Switzerland \\
\hline Турция & The e-Transformation Turkey Project since 2003 \\
\hline Великобритания & Digital Economy Act \\
\hline США & Many ICT initiatives form part of the Strategy for American Innovation \\
\hline
\end{tabular}

Источник: [https://cyberleninka.ru/article/n/komparativnyy-analiz-strategicheskih-aspektov-razvitiya-tsifrovoy-ekonomiki]

Российской Федерации»», которая была утверждена распоряжением Правительства Российской Федерации от 28 июля 2017 г. № 1632-р, и по сути представляет собой схожий документ созданный для обеспечения поддержки в реализации стратегии развития информационного общества, общества знаний, создания условий повышения доступности и качества товаров и услуг создаваемых в цифровой экономике [1].

Данный документ является фундаментальной правовой и стратегической основой для интеграции в мировую цифровую экосистему и создания условий для функционирования цифровой экономики, хотя в полной мере не формализует экономические фундаментальные теоретико-методологические аспекты для полного обеспечения процесса общественного воспроизводства в рамках глобальной цифровизации, потому исследования проводимые учёными - экономистами в этом направлении являются необходимой движущей силой для такого обеспечения.

\section{Библиографический список}

1. Указ Президента Российской Федерации от 09.05.2017 г. № 203 «О Стратегии развития информационного общества в Российской Федерации на 2017-2030 годы». http://kremlin.ru/acts/bank/41919/page/1

2. Абдрахманова Г.И., Вишневский К. О., Гохберг Л.М. и др.; науч. ред. Гохберг Л.М. Что такое цифровая экономика? Тренды, компетенции, измерение Ч-80 [Текст]: докл. к XX Апр. междунар. науч. конф. по проблемам развития экономики и общества, Москва, Нац. исслед. ун-т «Высшая школа экономики».- М.: Изд. дом Высшей школы экономики, 2019.- 82, [2] с. - 250 экз. - ISBN978-5-7598-1974-5 (в обл.).- ISBN978-57598-1898-4

3. Попов Евгений Васильевич, Семячков Константин Александрович Компаративный анализ стратегических аспектов развития цифровой экономики // Вестник Пгу. Серия: Экономика. 2018. № 1. URL: https:// cyberleninka.ru/article/n/komparativnyy-analiz-strategicheskih-aspektov-razvitiya-tsifrovoy-ekonomiki 
4. Bukht R., Heeks R., 2018. Digital Economy Policy in Developing Countries (DIODE). Development Implications of Digital Economies, Centre for Development Informatics Global Development Institute, SEED University of Manchester, Arthur Lewis Building, Manchester, M13 9PL, UK. https:/diode.network/publications/

5. Dahlman, C., Mealy, S. \& Wermelinger, M., 2016. Harnessing the Digital Economy for Developing Countries, OECD, Paris. http://www.oecd-ilibrary.org/docserver/download/4adffb24-en.pdf

6. GSMA 2019, URL: https://www.gsma.com/mobilemoneymetrics/ [Online Resource]

7. Sunil Bharti Mittal, India Economic Summit, 3-4 October 2019 New Delhi, India. Retrived from: https://www. weforum.org/events/world-economic-forum-on-india-2019 [Online Resource]

8. World Bank 2019, URL: http://data.worldbank.org/data-catalog/world-development-indicators 